\title{
STEAP4 Inactivation Correlates Poor Prognosis and might be a Possible Cause of steatotic Change in Hepatocellular Carcinoma, Detected by Triple- Combination Array Analysis
}

Fuminori Sonohara, Masamichi Hayashi, Mitsuhiro Hishida, Yoshikuni Inokawa, Mitsuro Kanda, Yoko Nishikawa, Shin Takeda, Hiroyuki Sugimoto, Tsutomu Fujii, Yasuhiro Kodera and Shuji Nomoto*

Department of Surgery II (Department of Gastroenterological Surgery), Nagoya University Graduate School of Medicine, Nagoya, Japan

*Corresponding author: Shuji Nomoto, Department of Surgery, Aichi-Gakuin University School of Dentistry, 2-11, Suemori-dori, Chikusa-ku, Nagoya, 464-8651, Japan, Tel: +81-52-7592167; Fax: +81-52-7592107; E-mail: snomoto@dpc.agu.ac.jp

Received date: Oct 8, 2014, Accepted date: Nov 24, 2014, Published date: Nov 30, 2014

Copyright: ( 2014 Sonohara F, et al. This is an open-access article distributed under the terms of the Creative Commons Attribution License, which permits unrestricted use, distribution, and reproduction in any medium, provided the original author and source are credited.

\begin{abstract}
In the present study, we originally designed triple-combination array analysis to identify tumor related genes in Hepatocellular Carcinoma (HCC). Using this method, the six transmembrane epithelial antigen of prostate family 4 (STEAP4), it was reported association with obesity and insulin-resistance, was detected as a candidate tumor suppressor gene. We found 32 of $48(66.7 \%)$ tumor tissues showed STEAP4 promoter hypermethylation, and its expression level was significantly reduced in tumor tissues $(p<0.0001)$. Methylated cases demonstrated significantly poorer recurrence-free survival $(p=0.0462)$ and overall survival $(p=0.0411)$. Triple-combination array analysis represents a useful technique for identifying novel tumor-related genes in HCC.
\end{abstract}

Keywords: Hepatocellular carcinoma; Expression array; Single nucleotide polymorphism array; Methylation array; Tumor-related gene; Six Transmembrane Epithelial Antigen of Prostate family 4 (STEAP4)

\section{Abbreviations:}

HCC: Hepatocellular Carcinoma; RT-PCR: Reverse TranscriptionPolymerase Chain Reaction; MSP: Methylation-Specific PCR; UMSP: Un-Methylation-Specific PCR

\section{Introduction}

Hepatocellular carcinoma (HCC) is the third most common cause of cancer deaths worldwide, and the incidence of this fatal disease continues to increase [1]. Stepwise accumulation of mutations in cancer-related genes and chromosomal alterations are known to be involved in human carcinogenesis [2]. Identification of genetic markers associated with the prognosis of HCC is therefore vital to improve HCC detection and patient survival. The development of high-throughput technologies including gene expression microarrays and Single Nucleotide Polymorphism (SNP) arrays that can simultaneously screen thousands of genes has opened a new era in translational research [3-5]. Resulting molecular-targeted therapies have markedly improved the prognosis for cancer patients. Clinical studies using the multi-targeted kinase inhibitor sorafenib have shown the potential of this approach for HCC [6,7]. Fresh surgical specimens can be used to determine the activity of cancer-related genes, though efficient and low-cost analytical methods are required. We recently reported on a new double-combination array method, which combines an SNP array with a gene expression microarray [8-13]. However, it has recently become evident that, in addition to genetic artifacts, epigenetic alterations involving aberrant methylation of gene promoters constitute an equally important mechanism of genomic instability in human cancers. A novel genome-wide DNA methylation platform was recently developed to determine the DNA methylation status of selected promoter regions [14]. We therefore used doublecombination array analysis in conjunction with the Illumina Infinium HumanMethylation 27 BeadChip platform (Illumina, San Diego, CA) to identify genes displaying altered gene expression in tumor tissue. This approach, referred to as a triple-combination array, detected many genes that showed differential expression between normal and tumor tissues, and identified many candidate tumor suppressor genes [15], including the metalloreductase STEAP4 gene (also known as TIARP or STAMP2). STEAP4-knockout mice exhibited overt inflammation and developed spontaneous metabolic disease on a regular diet, manifesting with insulin resistance, glucose intolerance, mild hyperglycemia, dyslipidemia, and fatty liver disease [16]. Although the majority of HCCs emerge from a background of chronic liver disease such as chronic hepatitis or liver cirrhosis, non-alcoholic fatty liver disease (NAFLD) is also becoming a common liver problem in clinical practice worldwide [17]. We therefore investigated STEAP4 as a possible candidate tumor suppressor gene in the present study.

\section{Materials and Methods}

\section{Sample collection and DNA preparation}

Nine HCC cell lines (HepG2, Hep3B, HLE, HLF, HuH1, HuH2, HuH7, PLC/PRF-5 and SK-Hep1) were obtained from the American Type Culture Collection (Manassas, VA). The cell lines were cultured in RPMI-1640 supplemented with $10 \%$ fetal bovine serum, and incubated in $5 \% \mathrm{CO}_{2}$ at $37^{\circ} \mathrm{C}$.

A 68-year-old woman with chronic hepatitis $\mathrm{C}$ was diagnosed with HCC in the right lobe and underwent liver resection. Tumor and adjacent non-tumor tissue specimens were excised and total RNA and DNA were extracted. Total RNA was sent to the manufacturer of Affymetrix to prepare it for expression array analysis. Genomic DNA was subjected to SNP-chip array analysis, and bisulfite-converted 
Citation: Sonohara F, Nomoto S, Hayashi M, Hishida M, Inokawa Y, et al. (2014) STEAP4 Inactivation Correlates Poor Prognosis and might be a Possible Cause of steatotic Change in Hepatocellular Carcinoma, Detected by Triple-Combination Array Analysis. J Carcinog Mutagen 5: 201. doi:10.4172/2157-2518.1000201

Page 2 of 8

DNA was subjected to methylation array analysis using the Illumina Infinium HumanMethylation 27 BeadChip. The tumor was confirmed pathologically to be HCC. RNA and DNA were extracted from an area consisting of $>80 \%$ cancerous cells.

HCC Tissue (HT) and Normal Tissue (NT) samples were obtained from 48 patients ( 43 males, 5 females) who underwent liver resection at Nagoya University Hospital, Nagoya, Japan, between 1994 and 2001. The patients were aged from 39-77 years (mean \pm SD, $62.4 \pm 7.9$ years). Thirty-eight patients had hepatitis $\mathrm{C}$ and seven had hepatitis $\mathrm{B}$. The median duration of follow-up was 89.7 months (range 17.9-213.1 months). All tissues were reviewed pathologically to confirm the diagnosis of HCC. Written informed consent, as required by the institutional review board, was obtained from all patients. The tissue samples were immediately frozen in liquid nitrogen and stored at $-80^{\circ} \mathrm{C}$ until required. Genomic DNA was obtained from the tissue samples by proteinase $\mathrm{K}$ digestion, followed by phenol/chloroform extraction.

\section{RNA isolation, microarray and gene chip affymetrix procedures}

Expression array and SNP array analyses were performed as described previously [8-10], using the total RNA and DNA extracted from the 68-year-old HCC patient's tissue samples.

\section{Methylation array platform}

The Illumina Infinium HumanMethylation27 BeadChip protocol requires $500 \mathrm{ng}$ to $1 \mu \mathrm{g}$ of bisulfite-converted DNA [14]. Methylation array analysis was performed as described previously $[15,18]$.

\section{Reverse transcription-polymerase chain reaction (RT-PCR)}

STEAP4 mRNA expression was analyzed by semi-quantitative and real-time RT-PCR. Total RNA $(10 \mu \mathrm{g})$ isolated from five HCC cell lines, primary HTs and NTs was used to generate cDNAs. The resulting cDNAs were then amplified using PCR primers for STEAP4 (sense, 5'-TCC AGT CAG GAG CAC TGG AT-3' in exon 3); antisense 5'-GGC TGC CAT GAG TGA TCC TT-3' in exon 4), which amplified a 134-bp product. Initial denaturation at $94^{\circ} \mathrm{C}$ for $5 \mathrm{~min}$ was followed by amplification with $27 \mathrm{cycles}$ of $94^{\circ} \mathrm{C}$ for $10 \mathrm{~s}, 60^{\circ} \mathrm{C}$ for $8 \mathrm{~s}$, and $72^{\circ} \mathrm{C}$ for 8s. RT-PCR of beta-actin was performed to confirm equal amounts of cDNA were used as templates. Each PCR product was loaded directly onto $3 \%$ agarose gels, stained with ethidium bromide, and visualized under UV illumination.

\section{Real-time quantitative RT-PCR analysis}

PCR was performed using a SYBR Green PCR Core Reagents kit (Perkin-Elmer Applied Biosystems, Foster City, CA) under the following conditions: 1 cycle at $50^{\circ} \mathrm{C}$ for $2 \mathrm{~min}, 1$ cycle at $95^{\circ} \mathrm{C}$ for 10 min, followed by 45 cycles at $95^{\circ} \mathrm{C}$ for $15 \mathrm{~s}$ and at $60^{\circ} \mathrm{C}$ for $30 \mathrm{~s}$. SYBR Green emission was detected in real time using an ABI prism 7000 Sequence Detector (Perkin-Elmer Applied Biosystems). The PCR primers were as described above for RT-PCR. For standardization, the expression of glyceraldehyde 3-phosphate dehydrogenase (GAPDH) was quantified in each sample. Quantitative RT-PCR was performed at least three times, including negative controls without template. STEAP4 expression was normalized to that of GAPDH in each sample.

\section{Methylation-specific PCR (MSP)}

DNA samples from HCC cell lines, HT and NT were subjected to bisulfite treatment. Briefly, $2 \mu \mathrm{g}$ of DNA was denatured with $\mathrm{NaOH}$ and modified with sodium bisulfite. DNA samples were then purified using Wizard purification resin (Promega Corp., Madison, WI), treated with $\mathrm{NaOH}$, precipitated with ethanol, and resuspended in water. Primer pairs were used to detect methylation (sense, 5'-GAG TTG TAG GCG CGG CGA AA-3'; antisense, 5'-CGT CCA ACG CCA ACG ATA CG-3'; 68-bp product) and un-methylation (sense, 5'-GTG TTG AGT TGT AGG TGT GGT-3'; antisense, 5'-CCA ACA CCA ACA ATA CAC ACC-3'; 70-bp product) of the STEAP4 promoter region near exon 1 . MSP amplification consisted of denaturation at $94^{\circ} \mathrm{C}$ for $5 \mathrm{~min}$ followed by 35 cycles at $94^{\circ} \mathrm{C}$ for $10 \mathrm{~s}, 60^{\circ} \mathrm{C}$ for $5 \mathrm{~s}$, and $72^{\circ} \mathrm{C}$ for $5 \mathrm{~s}$. Unmethylated-specific PCR (UMSP) amplification consisted of denaturation at $94^{\circ} \mathrm{C}$ for 5 min followed by 35 cycles at $94^{\circ} \mathrm{C}$ for $8 \mathrm{~s}, 58^{\circ} \mathrm{C}$ for $5 \mathrm{~s}$, and $72^{\circ} \mathrm{C}$ for $5 \mathrm{~s}$. The PCR products were loaded directly onto $3 \%$ agarose gels, stained with ethidium bromide, and visualized under UV illumination.

\section{Sequence analysis}

Bisulfite-treated genomic DNA from HCC cell lines was sequenced and subjected to PCR. The primer pairs for sequencing targeted the STEAP4 promoter region near exon 1 (sense, 5'-GTT GGG ATT TTT AGT TTG AA-3'; antisense, 5'-AAC CCA CCT AAA AAA AAA AC-3'; 229-bp product). PCR amplification consisted of denaturation at $94^{\circ} \mathrm{C}$ for $5 \mathrm{~min}$ followed by 35 cycles of $94^{\circ} \mathrm{C}$ for $10 \mathrm{~s}, 58^{\circ} \mathrm{C}$ for $10 \mathrm{~s}$ and $72^{\circ} \mathrm{C}$ for $15 \mathrm{~s}$. The PCR products were purified using a QIA quick Gel Extraction Kit (Qiagen, Hilden, Germany). The purified DNA fragments were subcloned into a TA cloning vector (Invitrogen, Carlsbad, CA). Six cloning samples were picked out from two HCC cell lines (HLF and HuH1). Each cloning DNA was mixed with $3 \mu \mathrm{l}$ of the specific primer (M13) and $4 \mu \mathrm{l}$ of Cycle Sequence Mix (ABI PRISM Terminator v1. 1 Cycle Sequencing Kit; Applied Biosystems, Foster City, CA). Samples were then subjected to the following cycling conditions: $95^{\circ} \mathrm{C}$ for $30 \mathrm{~s}$ followed by 25 cycles of $95^{\circ} \mathrm{C}$ for $15 \mathrm{~s}, 50^{\circ} \mathrm{C}$ for $15 \mathrm{~s}$, and $60^{\circ} \mathrm{C}$ for $4 \mathrm{~min}$, and then purified by ethanol precipitation. Sequence analysis was carried out using an Applied Biosystems $\mathrm{ABI} 310$, and sequence electropherograms were generated using $\mathrm{ABI}$ Sequence Analysis software version 3.0.

\section{5-Aza-2'-deoxycytidine (5-aza-dC) treatment}

To confirm that promoter hypermethylation was responsible for silencing of gene expression, the five HCC cell lines were treated with $1 \mu \mathrm{M}$ 5-aza-dC (Sigma-Aldrich, St. Louis, MO) to inhibit DNA methylation. Cells $(1.5 \times 106)$ were cultured for 6 days and medium was changed on days 1,3 , and 5 . Cells were harvested on day 6 , RNA was extracted, and RT-PCR was performed as described above.

\section{Western blotting analysis}

Cultured cells were washed twice with phosphate-buffered saline and lysed with lithium dodecyl sulfate buffer (Invitrogen). Protein lysates were resolved on $10 \%$ sodium dodecyl sulfate-polyacrylamide gels, electrotransferred to polyvinylidene fluoride membranes using iBlot $^{\oplus}$ Gel Transfer Device (Invitrogen) and blocked in 5\% non-fat dry milk. Membranes were immunoblotted overnight at $4^{\circ} \mathrm{C}$ with rabbit anti-STEAP4 antibody (SAB2900285; Sigma-Aldrich Biotechnology LP and Sigma-Aldrich Co., SL, USA) followed by peroxidaseconjugated secondary antibodies. Beta-actin was detected using a 
Citation: Sonohara F, Nomoto S, Hayashi M, Hishida M, Inokawa Y, et al. (2014) STEAP4 Inactivation Correlates Poor Prognosis and might be a Possible Cause of steatotic Change in Hepatocellular Carcinoma, Detected by Triple-Combination Array Analysis. J Carcinog Mutagen 5: 201. doi:10.4172/2157-2518.1000201

Page 3 of 8

mouse monoclonal anti-beta-actin antibody (Abcam plc, Cambridge, UK). Signals were detected by enhanced chemiluminescence (Lumivision PRO HSII, Aisin Seiki Co., LTD, Kariya, Japan).

\section{Immunohistochemistry}

STEAP4 protein expression was investigated by immunohistochemistry in the samples previously analyzed by arrays and in 40 well-preserved HCC samples. Cut sections were prepared from formalin-fixed and paraffin-embedded tissues for STEAP4 staining. Samples were treated with $3 \% \mathrm{H}_{2} \mathrm{O}_{2}$ to inhibit endogenous peroxidase, and then subjected to antigen retrieval using $10 \mathrm{mM}$ citrate buffer at $95^{\circ} \mathrm{C}$ for $10 \mathrm{~min}$ five times. Sections were incubated with Histofine SAB-PO(R) (Nichirei, Tokyo, Japan) for $10 \mathrm{~min}$ to limit non-specific reactivity, and then incubated with rabbit STEAP4 antibody (SAB2900285; Sigma-Aldrich Biotechnology LP and SigmaAldrich Co.) diluted 1:500 in ChemMatet antibody diluent (Dako, Copenhagen, Denmark) for $12 \mathrm{~h}$. All stains were developed for $15 \mathrm{~min}$ using liquid diaminobenzidine as the substrate (Nichirei). We determined staining properties using blood vessels as an integral control, and compared STEAP4 expression between HCC and corresponding noncancerous tissues. To avoid subjectivity, specimens were randomized and coded before analysis by two independent observers, who evaluated all specimens at least twice within a given interval to minimize intra-observer variation.

\section{Statistical analysis}

Continuous variables were expressed as medians (range) and comparisons were made using Mann-Whitney U-tests. Categorical variables were compared using $\chi^{2}$ or Fisher's exact tests, as appropriate. Overall survival rates were analyzed by Kaplan-Meier and log-rank tests. All statistical analyses were performed using JMP software version 9.0.2 (SAS International Inc., Cary, NC). The level of statistical significance was set at $\mathrm{p}<0.05$.

\section{Results}

\section{Expression, SNP, and methylation arrays}

To identify novel tumor-related genes in HCC, we first looked for genes with decreased expression levels in HCC samples compared with corresponding normal tissues. Expression array analysis revealed that STEAP4, which has been reportedly associated with metabolic syndrome, was strongly down-regulated in HCC tissues, by -4.2 and $-2.0(\log 2$ ratios) at two points in the expression array chip (Table 1).

\begin{tabular}{|l|l|l|l|l|l|l|l|l|}
\hline $\begin{array}{l}\text { Probe } \\
\text { Set ID }\end{array}$ & $\begin{array}{l}\text { Gene } \\
\text { Symbol }\end{array}$ & $\begin{array}{l}\text { Log2 } \\
\text { Ratio }\end{array}$ & $\begin{array}{l}\text { Normal } \\
\text { Signal }\end{array}$ & Detection & $\begin{array}{l}\text { Tumor } \\
\text { Signal }\end{array}$ & Detection & Probe ID & $\begin{array}{l}\text { Chromosomal } \\
\text { Location }\end{array}$ \\
\hline '225987_at & STEAP4 & -4.2 & 506.4 & $\mathrm{P}^{*}$ & 25.9 & $\mathrm{P}^{*}$ & HU133p2_35244 & ch.7q21.12 \\
\hline 220187_at & STEAP4 & -2.0 & 116.0 & $\mathrm{P}^{*}$ & 13.1 & $\mathrm{P}^{*}$ & HU133p2_29472 & ch.7q21.12 \\
\hline
\end{tabular}

Table 1: Decreased expression of STEAP4 gene in HCC samples by expression profiling. ${ }^{*}$ Detection of P indicated as positive signal.

Figure 1

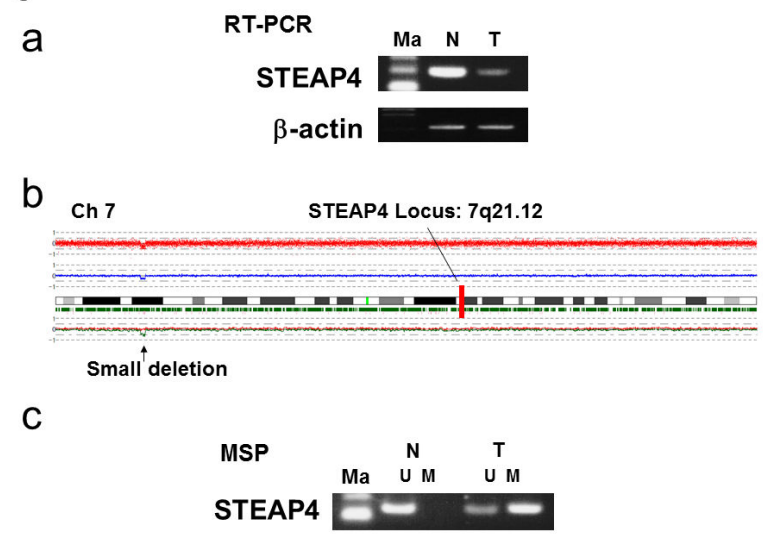

Figure 1: Triple-array analysis. Semi-quantitative RT-PCR, SNP array, and MSP results for STEAP4 gene in the case used for triplearray analysis. (a) Downregulation of STEAP4 in tumor sample compared with corresponding normal tissue. (b) Small deletion was shown at $7 \mathrm{p}$, but no deletion or amplification was detected at 7q21.12 (STEAP4 locus). (c) Promoter hypermethylation was only seen in the tumor sample.
Reduced expression of STEAP4 mRNA in tumor tissue was confirmed by semi-quantitative RT-PCR in the case whose samples were used for array analysis (Figure 1a).

SNP array analysis revealed deletions in $3 \mathrm{q}, 8 \mathrm{p}, 11 \mathrm{q}, 12 \mathrm{p}, 12 \mathrm{q}, 16 \mathrm{p}$, $17 p, 19 p$, and the $X$ chromosome, and chromosomal gains in $1 \mathrm{q}, 3 \mathrm{q}$, $11 \mathrm{q}, 12 \mathrm{p}$, and 12q. There was a small deletion in $7 \mathrm{p}$, but no deletions or amplifications in 7q, which contains the STEAP4 gene (Figure 1b). We also examined the SNP array at the STEAP4 gene locus at $7 \mathrm{q} 21.12$ in detail and detected three SNPs in the STEAP4 region; two of these three SNPs, SNP_A-4294792 and SNP_A-4199919, showed heterozygous signals in both normal and tumor tissues, indicating that both alleles were retained at this locus (Table 2). STEAP4 gene expression was thus decreased with no loss of heterozygosity.

Methylation array analysis showed continuous $\beta$-values of 0.870 for tumor tissue versus 0.160 for normal tissue, indicating a high degree of methylation in the HCC sample (Table 1).

\section{Effects of inhibiting methylation on STEAP4 expression in HCC cell lines}

To confirm that promoter hypermethylation led to silencing of STEAP4 gene expression, we compared mRNA expression levels before and after 5-aza-dC treatment in nine HCC cell lines. STEAP4 expression in all nine cell lines was clearly re-activated by 5 -aza-dC treatment, as shown by semi-quantitative RT-PCR (Figure 2a). 
Citation: Sonohara F, Nomoto S, Hayashi M, Hishida M, Inokawa Y, et al. (2014) STEAP4 Inactivation Correlates Poor Prognosis and might be a Possible Cause of steatotic Change in Hepatocellular Carcinoma, Detected by Triple-Combination Array Analysis. J Carcinog Mutagen 5: 201. doi:10.4172/2157-2518.1000201

Page 4 of 8

\begin{tabular}{|l|l|l|l|l|l|l|}
\hline Probe_Set_ID & Chromosome & Physical_Position & Normal Call & Normal Confidence & Tumor Call & Tumor Confidence \\
\hline SNP_A-1961351 & 7 & 25961384 & AA & $0.039063^{*}$ & AA & $0.015625^{*}$ \\
\hline SNP_A-4294792 & 7 & 25965543 & AB & $0.046875^{*}$ & AB & $0.046875^{*}$ \\
\hline SNP_A-4199919 & 7 & 25966662 & AB & $0.046875^{*}$ & AB & $0.015625^{*}$ \\
\hline
\end{tabular}

Table 2: Results of SNP signals at the STEAP4 gene locus. ${ }^{\star}$ Lower value of the confidences than 0.05 indicated accuracy.

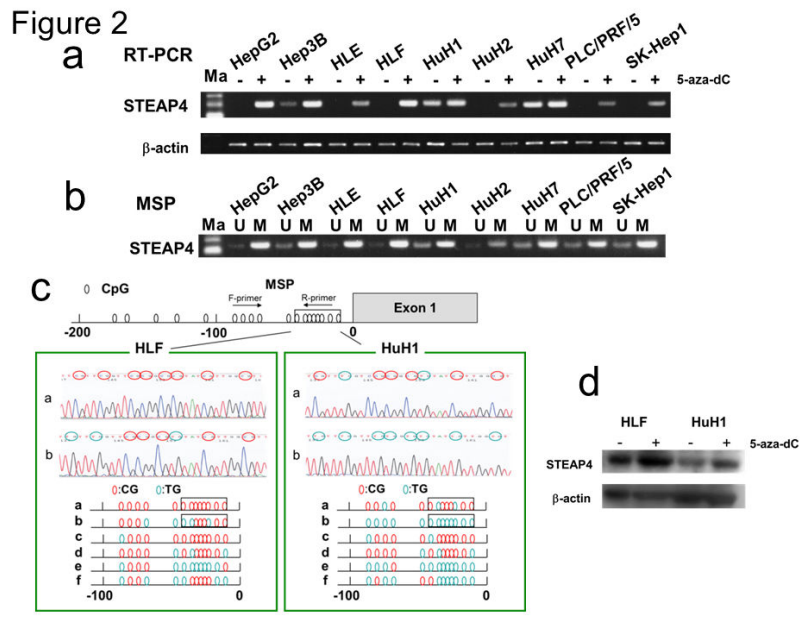

Figure 2: Hypermethylation in HCC cell lines. Semi-quantitative RT-PCR and MSP or UMSP results for STEAP4 gene in HCC cells. (a) STEAP4 expression was reactivated in HCC cells by 5 -aza-dC. DNA quality was normalized to beta-actin. (b) Methylation status of STEAP4 gene in HCC cell lines. Methylated and unmethylated bands occurred in all nine cell lines, indicating partial methylation. U: unmethylated, M: methylated. (c) Sequence analysis of bisulfitetreated DNA in STEAP4 promoter region. Methylation statuses of the $13 \mathrm{CpG}$ islands in the six (a-f) clones by TA cloning method between -1 and -100 from the transcription initiation site of STEAP4 exon 1 are shown. CpG islands in the promoter region were mostly methylated in HLF cells, but mostly unmethylated in $\mathrm{HuH} 1$ cells. The figures in the sequence analysis in the middle show the results for the $\mathrm{CpG}$ islands between -15 and -48 corresponding to the boxes in the upper figure. Red circles indicate methylated $\mathrm{CpG}$ islands and blue circles indicate unmethylated $\mathrm{CpG}$ islands. (d) Immunoblotting revealed that STEAP4 protein expression was re-activated by 5 -aza-dC treatment in HLF and $\mathrm{HuH} 1$ cells.

\section{MSP and UMSP in HCC cell lines and clinical samples}

We designed primers for MSP and UMSP to check the methylation status of the HCC sample used for the arrays and of the nine HCC cell lines. Bands corresponding to methylated STEAP4 only were obtained from the tumor tissue in the original case, while both methylated and unmethylated bands were detected in all nine cell lines (Figure 2b), indicating partial methylation in all nine HCC cell lines. MSP subsequently confirmed hypermethylation of the STEAP4 gene in tumor tissue from the 68-year-old patient whose DNA had been used for the methylation array (Figure 1c).

\section{Sequence analysis}

To validate the MSP amplification results, we sequenced the STEAP4 promoter region in HLF and HuH1 cells. Six clones showed a different methylation status in both HLF and HuH1 cells, suggesting that they were partially methylated and confirming the MSP and UMSP results (Figure 2c).

\section{Western blotting}

STEAP4 protein expression in HLF and $\mathrm{HuH} 1$ cells was reactivated by 5 -aza-dC treatment, as determined by western blotting, consistent with RT-PCR results (Figure $2 \mathrm{~d}$ ).

\section{MSP and UMSP of normal and tumor tissues from HCC patients}

Thirty-two of 48 (66.7\%) tumor samples displayed STEAP4 promoter hypermethylation (Figures $3 \mathrm{a}$ and $\mathrm{b}$ ), compared with only four of 48 normal samples. Forty-five of the 48 cases were hepatitispositive, but two of the four cases with methylation in the corresponding normal tissue were hepatitis-negative. 
Citation: Sonohara F, Nomoto S, Hayashi M, Hishida M, Inokawa Y, et al. (2014) STEAP4 Inactivation Correlates Poor Prognosis and might be a Possible Cause of steatotic Change in Hepatocellular Carcinoma, Detected by Triple-Combination Array Analysis. J Carcinog Mutagen

\section{Figure 3}
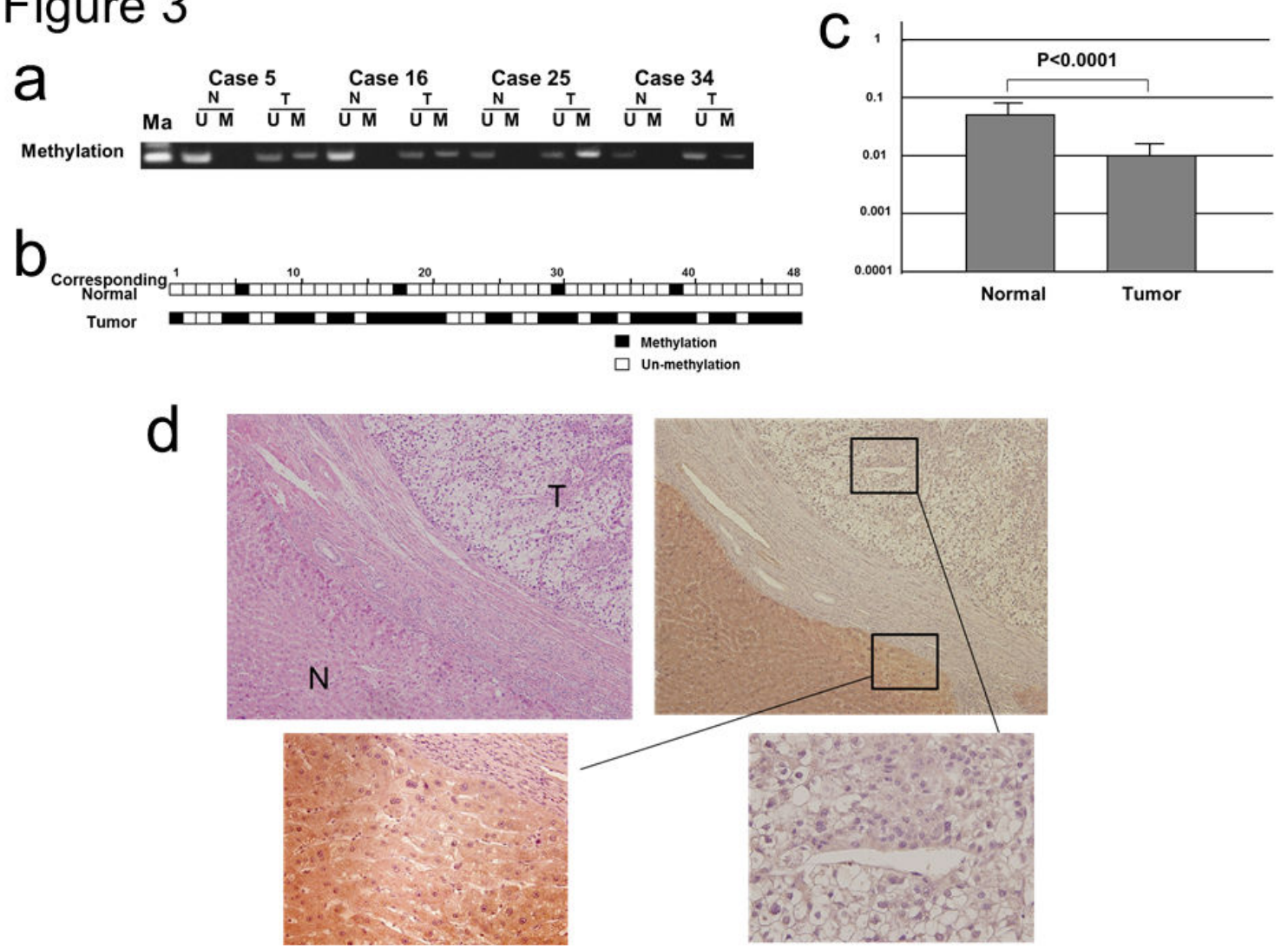

Figure 3: Methylation status and expression of STEAP4 in HCC primary samples. Representative results of methylation status in primary HCC tissues. STEAP4 was largely methylated in tumor tissues and unmethylated in corresponding normal samples. (b) Thirty-two of 48 (66.7\%) primary HCC samples showed hypermethylation of STEAP4. Only four showed methylation in the corresponding normal samples, all of which also showed methylation in the tumor tissues. Black box indicates hypermethylation; open box indicates unmethylation. (c) Expression levels of STEAP4 mRNA, divided by GAPDH levels, in normal and tumor tissues, examined by quantitative RT-PCR. Total STEAP4 expression (relative to GAPDH) was significantly lower in tumor tissues than normal samples (median STEAP4/GAPDH ratio, 0.043 vs. $0.010 ; \mathrm{p}<0.001$ ). (d) Immunohistochemical staining of HCC case. Tumor tissue was poorly-stained with steatic degeneration, whereas normal hepatocytes were stained cytoplasmically.

\section{Real-time quantitative RT-PCR analysis of HCC patients}

Overall STEAP4 expression (relative to GAPDH) was significantly lower in tumor tissues compared with normal samples (median STEAP4/GAPDH ratio, 0.043 vs. 0.010; $\mathrm{p}<0.0001$ ) (Figure 3c), and 42 of the 48 HCC samples (88.0\%) displayed lower STEAP4 expression than normal tissues.

\section{Immunohistochemical staining of STEAP4}

STEAP4 protein levels were reduced in cancerous relative to noncancerous components of samples used for array analysis and in 37 of 40 (93\%) HCC samples. There was a significant correlation between reduced protein levels in tumor tissues and reduced mRNA levels measured by real time RT-PCR $(p<0.001)$. As shown in the representative examples, tumor tissues were poorly stained with steatic degeneration (Figure 3d), whereas normal hepatocytes were stained cytoplasmically.

\section{Correlation between STEAP4 promoter hypermethylation and clinicopathological characteristics in HCC patients}

Significant correlations were identified between epigenetic methylation in tumor tissue and hepatitis $B$ virus (HBV) positivity $(\mathrm{p}=0.042)$, severe cirrhosis $(\mathrm{p}=0.004)$, higher alfa-fetoprotein (AFP) levels $(\mathrm{p}=0.022)$, and lower albumin levels $(\mathrm{p}<0.001)$ (Table 3$)$.

Univariate analysis of recurrence-free survival (RFS) identified significant correlations with methylation $(\mathrm{p}<0.001)$, AFP $(\mathrm{p}=0.004)$, Child-Pugh status $(\mathrm{p}=0.017)$, and serum albumin level $(\mathrm{p}<0.001)$. Multivariate analysis showed that RFS was most strongly correlated with methylation status $(\mathrm{p}<0.001)$, and overall survival was significantly correlated only with methylation status (Table 4 ). 
Citation: Sonohara F, Nomoto S, Hayashi M, Hishida M, Inokawa Y, et al. (2014) STEAP4 Inactivation Correlates Poor Prognosis and might be a Possible Cause of steatotic Change in Hepatocellular Carcinoma, Detected by Triple-Combination Array Analysis. J Carcinog Mutagen 5: 201. doi:10.4172/2157-2518.1000201

Page 6 of 8

\begin{tabular}{|c|c|c|c|c|c|c|c|c|}
\hline \multirow[t]{2}{*}{ Probe ID } & \multirow{2}{*}{$\begin{array}{l}\text { Gene } \\
\text { Symbol }\end{array}$} & \multirow[t]{2}{*}{ Sample } & \multirow{2}{*}{$\begin{array}{l}\text { Methylation } \\
\text { Value }\end{array}$} & \multicolumn{3}{|c|}{ Status } & \multirow[t]{2}{*}{ Confidence } & \multirow{2}{*}{$\begin{array}{l}\text { Chromosomal } \\
\text { Location }\end{array}$} \\
\hline & & & & Total & Unmethylated & Methylated & & \\
\hline \multirow[t]{2}{*}{ cg005643 } & \multirow[t]{2}{*}{ STEAP4 } & Normal & 0.160 & 2327 & 1960 & 367 & $3.678 \mathrm{E}-38^{*}$ & \multirow[t]{2}{*}{ ch.7q21.12 } \\
\hline & & Tumor & 0.870 & 4063 & 440 & 3623 & $3.678 \mathrm{E}-38^{*}$ & \\
\hline
\end{tabular}

Table 3: The result of Methylation Array analysis of the HCC sample. ${ }^{*}$ The value of the confidences indicated accurate.

\begin{tabular}{|c|c|c|c|c|}
\hline \multicolumn{2}{|c|}{ Variables } & \multirow{2}{*}{$\begin{array}{l}\text { Methylation+(32) } \\
18\end{array}$} & \multirow{2}{*}{$\begin{array}{l}\text { Methylation- } \\
\text { (16) }\end{array}$} & \multirow[b]{2}{*}{0.414} \\
\hline Age & $<65$ & & & \\
\hline & $>65$ & 14 & 9 & \\
\hline & HBV & 7 & 0 & $0.042^{*}$ \\
\hline & $\mathrm{HCV}$ & 23 & 15 & \\
\hline \multirow[t]{2}{*}{ Patho } & mod+poor & 29 & 14 & 0.738 \\
\hline & well & 3 & 2 & \\
\hline \multirow[t]{2}{*}{ Size } & $<50$ & 23 & 12 & 0.818 \\
\hline & $>50$ & 9 & 4 & \\
\hline \multirow[t]{2}{*}{ Size } & $<30$ & 15 & 7 & 0.838 \\
\hline & $>30$ & 17 & 9 & \\
\hline \multirow[t]{2}{*}{ Size } & $<20$ & 7 & 1 & 0.171 \\
\hline & $>20$ & 25 & 15 & \\
\hline \multirow[t]{17}{*}{ Number } & solitary & 21 & 10 & 0.831 \\
\hline & multiple & 11 & 6 & \\
\hline & eg & 26 & 15 & 0.462 \\
\hline & ig & 4 & 1 & \\
\hline & fc- & 5 & 2 & 0.772 \\
\hline & fc+ & 27 & 14 & \\
\hline & fc-inf- & 5 & 2 & 0.741 \\
\hline & fc-inft & 26 & 14 & \\
\hline & vp- & 25 & 14 & 0.553 \\
\hline & $v p+$ & 6 & 2 & \\
\hline & vv- & 31 & 15 & 0.159 \\
\hline & $v v^{+}$ & 0 & 1 & \\
\hline & vp or vv- & 25 & 13 & 0.802 \\
\hline & vp or vv+ & 7 & 3 & \\
\hline & z1 & 12 & 13 & $0.004^{*}$ \\
\hline & z2 & 20 & 3 & \\
\hline & stage12 & 22 & 10 & 0.665 \\
\hline
\end{tabular}

\begin{tabular}{|l|l|l|l|l|}
\hline \multirow{4}{*}{ AFP } & stage34 & 10 & 6 & \\
\cline { 2 - 6 } & $<20$ & 9 & 10 & $0.022^{*}$ \\
\cline { 2 - 5 } & $>20$ & 23 & 6 & \\
\cline { 2 - 5 } & ChildA & 30 & 13 & 0.181 \\
\cline { 2 - 5 } & ChildB & 2 & 3 & \\
\hline \multirow{3}{*}{ Alb } & $<3.5$ & 5 & 16 & $<0.001^{*}$ \\
\cline { 2 - 5 } & $>3.5$ & 27 & 0 & \\
\hline \multirow{3}{*}{ PT } & $<80$ & 21 & 11 & 0.829 \\
\cline { 2 - 6 } & $>80$ & 11 & 5 & \\
\hline \multirow{3}{*}{ R15 } & $<10$ & 13 & 4 & 0.286 \\
\cline { 2 - 6 } & $>10$ & 19 & 12 & \\
\hline \multirow{2}{*}{ Damage } & $\mathrm{A}$ & 18 & 11 & 0.404 \\
\hline
\end{tabular}

Table 4: Clinicopathological Features and Results of STEAP4 Hypermethylation in HCC. patho: pathological findings, mod+poor: moderately or poorly differentiated, well: well differentiated, Eg: expansive growth, ig: infiltrative growth, fc: formation of capsule, fcinf: infiltration to capsule, vp: portal vessel invasion, vv: venus vessel invasion, z: liver cirrhosis, AFP: alpha feto protein, Alb: albumin value, PT: prothrombin time, R15: ICG R15, damage: degree of liver damage.

STEAP4 hypermethylation was significantly correlated with poorer RFS ( $p=0.0462$ ) (Figure 4a). STEAP4 hypermethylation was also significantly correlated with poor prognosis $(\mathrm{p}=0.0411)$ (Figure $4 \mathrm{~b})$.

\section{Discussion}

Obesity is widely recognized as a significant risk factor for the development of many types of cancer, including HCC. NAFLD is becoming a major liver problem in clinical practices worldwide. The rising prevalence of risk factors associated with non-alcoholic steatohepatitis (NASH) can partially account for the increasing incidence of cryptogenic cirrhosis and subsequent HCC. NAFLD occurs in the setting of obesity, hyperlipidemia, and diabetes, which constitute metabolic syndrome [19].

Steatosis is detected in liver biopsies from patients with hepatitis $\mathrm{C}$ more frequently than other chronic liver diseases such as chronic hepatitis B and autoimmune hepatitis. Steatosis is also 2.5 times more prevalent in patients with hepatitis $\mathrm{C}$ than in the general population, and hepatitis $\mathrm{C}$ virus (HCV) genotype 3 has been shown to be independently associated with hepatocellular steatosis in patients with chronic hepatitis C. Furthermore, the severity of steatosis is directly 
Citation: Sonohara F, Nomoto S, Hayashi M, Hishida M, Inokawa Y, et al. (2014) STEAP4 Inactivation Correlates Poor Prognosis and might be a Possible Cause of steatotic Change in Hepatocellular Carcinoma, Detected by Triple-Combination Array Analysis. J Carcinog Mutagen 5: 201. doi:10.4172/2157-2518.1000201

Page 7 of 8

related to HCV RNA load. This relationship between HCV viral load and severity of steatosis has not been observed for other $\mathrm{HCV}$ genotypes [20]. This HCV-induced steatosis might be one cause of hepatocarcinogenesis.

\section{Figure 4}

\section{a}

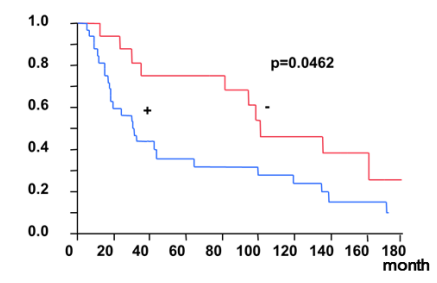

b

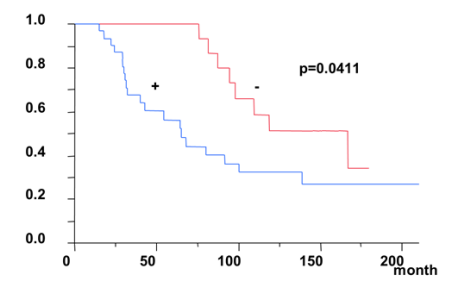

Figure 4: Recurrence-free survival and overall survival stratified by STEAP4 methylation status. (a) Methylation of STEAP4 in tumor samples was significantly correlated with poor recurrence-free survival compared with unmethylated cases ( $\mathrm{p}=0.0462)$. (b) Methylation of STEAP4 in tumor tissues was significantly correlated with poorer prognosis compared with unmethylated cases $(\mathrm{p}=0.0411)$.

NAFLD is closely associated with insulin resistance and several features of metabolic syndrome. Insulin resistance and lipotoxicity are distinct molecular mechanisms that may promote the development of HCC in NAFLD. Deregulation of the metabolic effects of insulin results in excessive activation of proliferative cell signaling cascades that remain responsive to insulin action, and which have been implicated in the development of HCC. Moreover, hyperinsulinemia results in reduced hepatic synthesis of insulin-like growth factor (IGF)-binding protein-1 and increased bioavailability of IGF-1, which further promotes cellular proliferation and inhibits apoptosis [21]. Although STEAP4-knockout mice were only reported to develop metabolic syndrome, it is possible that further observations might identify various cancers. In addition, STEAP4 knockdown had no obvious effect on cell proliferation or invasion in vitro, and we need to further investigate genes that affect cancer progression in vivo, in relation to other tissues or hormones such as insulin.

Well-differentiated early-stage HCCs are characterized by frequent fatty and/or clear changes in cancer cells. Changes to STEAP4 might occur during these early stages of hepatocarcinogenesis. Varying degrees of diffuse fatty change are observed in approximately $40 \%$ of tumors $<2 \mathrm{~cm}$ in diameter, and decrease with increasing tumor size. HCC is known to often present with histological variations within a single tumor nodule, and although most small HCC nodules $(<1.5 \mathrm{~cm}$ diameter) consist uniformly of well-differentiated cancerous tissues, about $40 \%$ of nodules of $1.5-3 \mathrm{~cm}$ in diameter are composed of more than two cancerous tissues with different histological grades, mostly well-differentiated and moderately-differentiated cancer tissues. Lessdifferentiated cancerous tissues are always located inside these HCC nodules and are surrounded by well-differentiated tissues. The well- differentiated component diminishes as tumor size increases, and welldifferentiated cancerous tissues are rare in tumors $>3 \mathrm{~cm}$ in diameter [22]. This might explain why STEAP4 methylation was frequently found in moderately- or poorly-differentiated HCCs in the current study.

In addition to steatotic changes, Tamura at al. investigated the possible roles of STEAP4 in cancer progression. They found that STEAP4 regulated the activity of focal adhesion kinase through Y397 phosphorylation. They also showed that $\mathrm{CpG}$ sequences in the STEAP4 promoter region were frequently methylated in prostate cancer cells [23]. Shen et al. studied genome-wide methylation profiles in HCC and found frequent hypermethylation of the STEAP4 gene promoter [24].

The current study revealed a significant correlation between STEAP4 methylation and poor prognosis. However, it is necessary to consider not only metastasis of these resected tumors, but also the prognosis regarding the potential multicentric recurrence of another clonal cancer in the liver. Previous studies showed that multicentric recurrences were more common than metastases from the original resected lesion [25,26]. STEAP4 promoter hypermethylation was significantly correlated with low albumin levels and more severe cirrhosis, suggesting that aberrant methylation occurred in patients with poor liver function. It is therefore possible that the poor prognosis in methylated cases was associated with both the phenotype of the resected tumor and a tendency for multicentric recurrence. Insulin resistance is also present in steatotic livers, which may further contribute to cancer proliferation and a poor prognosis. Although no such cases were included in the present study, STEAP4 methylation has also been demonstrated in normal and cancerous samples of HCC originating in NASH. STEAP4 moderates adipokine expression, and may thus be involved in NASH carcinogenesis.

These results suggest that background liver function is an important element in predicting the occurrence and prognosis of HCC. Further studies are needed to examine background gene alterations in the liver, including aberrant gene expression or methylation, and chromosomal abnormalities.

Using triple-array analysis, this study identified STEAP4 as a potentially useful gene for predicting HCC carcinogenesis and prognosis. This method may thus be useful for investigating other cancer-related genes.

\section{Acknowledgement}

This work was supported by Japan Society for the Promotion of Science (JSPS) KAKENHI Grant-in-Aid for Scientific Research (C) Number 22591427.

\section{References:}

1. Nishida N, Goel A (2011) Genetic and epigenetic signatures in human hepatocellular carcinoma: a systematic review. Curr Genomics 12: 130-137.

2. Nishida N, Nishimura T, Ito T, Komeda T, Fukuda Y, et al. (2003) Chromosomal instability and human hepatocarcinogenesis. Histol Histopathol 18: 897-909.

3. Schena M, Shalon D, Davis RW, Brown PO (1995) Quantitative monitoring of gene expression patterns with a complementary DNA microarray. Science 270: 467-470. 
Citation: Sonohara F, Nomoto S, Hayashi M, Hishida M, Inokawa Y, et al. (2014) STEAP4 Inactivation Correlates Poor Prognosis and might be a Possible Cause of steatotic Change in Hepatocellular Carcinoma, Detected by Triple-Combination Array Analysis. J Carcinog Mutagen 5: 201. doi:10.4172/2157-2518.1000201

Page 8 of 8

4. $\quad$ Lau WY, Lai PB, Leung MF, Leung BC, Wong N, et al. (2000) Differential gene expression of hepatocellular carcinoma using cDNA microarray analysis. Oncol Res 12: 59-69.

5. Wang DG, Fan J B, Siao CJ, Berno A, Young P, et al. (1998) Lander, Large-scale identification, mapping and genotyping of single-nucleotide polymorphisms in the human genome. Science 280 1077-1082

6. Cheng AL, Kang YK, Chen Z, Tsao CJ, Qin S, et al. (2009) Efficacy and safety of sorafenib in patients in the Asia-Pacific region with advanced hepatocellular carcinoma: a phase III randomised, double-blind, placebocontrolled trial. Lancet Oncol: 25-34

7. Llovet J M, Ricci S, Mazzaferro V, Hilgard P, Gane E, et al. (2008) SHARP Investigators Study Group, Sorafenib in advanced hepatocellular carcinoma, N Engl J Med 359: 378-390

8. Kanda M, Nomoto S, Okamura Y, Nishikawa Y, Sugimoto H, et al. (2009) Detection of metallothionein $1 G$ as a methylated tumor suppressor gene in human hepatocellular carcinoma using a novel method of double combination array analysis. Int J Oncol 35: 477-483

9. Okamura Y, Nomoto S, Kanda M, Li Q, Nishikawa Y, et al. (2010) Leukemia inhibitory factor receptor (LIFR) is detected as a novel suppressor gene of hepatocellular carcinoma using double-combination array. Cancer Lett 289 (2010) 170-177

10. Nomoto S, Kanda M, Okamura Y, Nishikawa Y, Qiyong L, et al. (2010) Epidermal growth factor-containing fibulin-like extracellular matrix protein 1, EFEMP1, a novel tumor-suppressor gene detected in hepatocellular carcinoma using double combination array analysis. Ann Surg Oncol: 923-932

11. Okamura Y, Nomoto S, Kanda M, Hayashi M, Nishikawa Y, et al. (2011) Reduced expression of reelin (RELN) gene is associated with high recurrence rate of hepatocellular carcinoma. Ann Surg Oncol 18: 572-579.

12. Kanda M, Nomoto S, Okamura Y, Hayashi M, Hishida M, et al. (2011) Promoter hypermethylation of fibulin 1 gene is associated with tumor progression in hepatocellular carcinoma. Mol Carcinog 50: 571-579.

13. Hayashi M, Nomoto S, Kanda M, Okamura Y, Nishikawa Y, et al. (2012) Identification of the A kinase anchor protein 12 (AKAP12) gene as a candidate tumor suppressor of hepatocellular carcinoma. J Surg Oncol 105: 381-386.

14. Bibikova M, Fan JB (2009) GoldenGate assay for DNA methylation profiling. Methods Mol Biol 507: 149-163.
15. Okamura Y, Nomoto S, Hayashi M, Hishida M, Nishikawa Y, et al. (2011) Identification of the bleomycin hydrolase gene as a methylated tumor suppressor gene in hepatocellular carcinoma using a novel triplecombination array method. Cancer Lett 312:150-157

16. Wellen KE, Fucho R, Gregor MF, Furuhashi M, Morgan C, et al. (2007) Coordinated regulation of nutrient and inflammatory responses by STAMP2 is essential for metabolic homeostasis. Cell 129: 537-548.

17. Williams R (2006) Global challenges in liver disease. Hepatology 44: 521-526.

18. Takai D, Jones PA (2003) The CpG island searcher: a new WWW resource. In Silico Biol 3: 235-240.

19. Chuang SC, La Vecchia C, Boffetta P (2009) Liver cancer: descriptive epidemiology and risk factors other than $\mathrm{HBV}$ and $\mathrm{HCV}$ infection. Cancer Lett 286: 9-14.

20. Yoon EJ, Hu KQ (2006) Hepatitis C virus (HCV) infection and hepatic steatosis. Int J Med Sci 3: 53-56.

21. Baffy G, Brunt EM, Caldwell SH (2012) Hepatocellular carcinoma in non-alcoholic fatty liver disease: an emerging menace. J Hepatol 56: 1384-1391.

22. Kojiro M, Yano H, Nakashima O (1996) Pathology of early hepatocellular carcinoma: progression from early to advanced. Semin Surg Oncol 12: 197-203.

23. Tamura T, Chiba J (2009) STEAP4 regulates focal adhesion kinase activation and CpG motifs within STEAP4 promoter region are frequently methylated in DU145, human androgen-independent prostate cancer cells. Int J Mol Med 24: 599-604

24. Shen J, Wang S, Zhang YJ, Kappil M, Wu HC, et al. (2012) Genome-wide DNA methylation profiles in hepatocellular carcinoma. Hepatology 55: 1799-1808.

25. Nomoto S, Yamashita K, Koshikawa K, Nakao A, Sidransky D (2002) Mitochondrial D-loop mutations as clonal markers in multicentric hepatocellular carcinoma and plasma. Clin Cancer Res 8: 481-487.

26. Nomoto S, Kinoshita T, Kato K, Otani S, Kasuya H, et al. (2007) Hypermethylation of multiple genes as clonal markers in multicentric hepatocellular carcinoma. Br J Cancer 97: 1260-1265. 